\title{
CONSIDERACÕES SOBRE AS IMAGENS DA REPRESENTAÇÃO TEATRAL DE EM BUSCA DO TEMPO PERDIDO
}

\author{
Manoel Moacir ${ }^{1}$
}

\section{Resumo}

$\mathrm{O}$ artigo apresenta diversas perspectivas sobre a construção das imagens teatrais nos primeiros volumes de $\mathrm{Em}$ busca do tempo perdido, de Marcel Proust. A primeira se conjuga a uma leitura crítica de Samuel Beckett; a segunda parte do cruzamento entre filosofia e as relações amorosas do livro, que dão o mote para a nota de conclusão, sobre a veia cômica do narrador.

Palavras-chave: imagens teatrais, amor, Proust.

\section{Abstract}

The following article presents different perspectives on the construction of the theatrical images in the first volumes of In search of a lost time, by Marcel Proust. The first one follows a critical reading by Samuel Beckett; the second crosses philosophy and love relationships within the book, which leads to our conclusion note, about the comical approach of the narrator.

Keywords: theatrical images, love, Proust.

\section{Da desilusão com La Berma a Beckett ${ }^{2}$}

O que nos têm a dizer as imagens do teatro de Em busca do Tempo Perdido, de Proust? Movidos por essa questão inicial e com uma leitura atenta aos três primeiros volumes da Busca, pretendemos trazer à tona um dos temas caros a esse ciclo romanesco, num corte que atravessa as duas linguagens afins: a literária e a teatral, que por vezes fundem-se numa só pelos traçados de uma escrita cênica.

Num dos primeiros episódios de $\grave{A}$ sombra das raparigas em flor, o narrador encontra-se inquieto para assistir pela primeira vez à grande atriz La Berma, que fará o papel principal de Fedra, tragédia de Racine. A ânsia para vê-la em cena, provocada à princípio por comentários entusiasmados de um amigo da família e por um cartaz, leva-o a recitar alguns versos dessa peça que ele já conhecia e a imaginar as entonações e os acentos empregados

${ }^{1}$ Mestre em Artes Cênicas pelo Programa de Pós-Graduação em Artes da ECAUSP. Professor do Curso de Belas Artes (UNIFOR). Membro do Grupo de trabalho "Territórios e fronteiras" da Associação Brasileira de Pesquisa e Pós-Graduação em Artes Cênicas (ABRACE) e do Grupo de Pesquisa Cênica (UECE).

${ }^{2}$ Essa primeira parte do artigo foi elaborada a partir do primeiro capítulo de minha dissertação de mestrado "Os silêncios na (dês-)composição da cena: poéticas de criação de e a partir de Samuel Beckett"

(2009), no qual discuto os ensaios de Beckett sobre a obra de Proust e James Joyce. 


\section{Urdimento}

3"Desejaria - para poder aprofundála, para tratar de descobrir o que tinha de belo - fazer parar, imobilizar por longo tempo diante de mim cada entonação da artista, cada expressão de sua fisionomia" (PROUST, 2006, p. 40).

4"Agora ele vê sua lamentada deficiência para a observação artística como uma série de 'inspiradas omissões' e a obra de arte como não sendo nem criada nem escolhida, mas descoberta, revelada, escavada, preexistente no interior do artista, uma lei da natureza. A única realidade é fornecida por hieróglifos traçados pela percepção inspirada (identificação de sujeito e objeto)" (BECKETT, 2003, p. 89). na atuação da famosa atriz, tidos como reveladores de uma "divina Beleza" e de verdades que o tirariam de sua "inútil existência”, desde então permeada por doenças que lhe impunham cuidados e alguma reclusão. Vê-la significaria uma apoteose, na qual mais do que regozijar-se intelectualmente ou procurar perfeição em sua interpretação o narrador de Proust mataria sua curiosidade diante de um signo ainda não decifrado, sequer visto: "implacável Divindade sem rosto e sem nome” (PROUST, 2006, p. 33-34).

O que se segue na tão esperada matinée é um espetáculo de pequenas convenções sociais, em que a própria imagem de La Berma, vista pela lente do monóculo ou não, aparece sem nuances, rápida, perdida entre as recitações mais coloridas dos outros atores; em tom menor. E, no entanto, o que o narrador escuta sobre o que vê são elogios à sua presença virtuosística e à decoração do cenário. Desapontado, imaginaria outra disposição ${ }^{3}$, em que pudesse aprofundar a percepção do que mais gostasse, apreciando a peça quadro a quadro e deixando de sentir-se como parte de "um meio acústico que apenas tinha importância na medida em que era favorável às inflexões daquela voz” (PROUST, 2006, p. 39).

Proust observa detalhadamente certos usos dos elementos que compõem o espetáculo nos diversos momentos de sua recepção, desde o aviso de fechamento da sala e do fechar e abrir das cortinas aos aplausos e vaias vindos da platéia em reação às atitudes de La Berma e cia. Na ida ao teatro, toda uma encenação social é feita para que o foco recaia sobre a figura de Berma, a qual passa a encarnar o contraponto desse desejo que esperava ser continuado pelo narrador. A quebra se dá dentro de um pacto de sobrevivência de acordo com as mudanças que ocorrem na narrativa, para suspender a vigilância do hábito. La Berma é, pois, uma convenção habitual (teatral) que se desvela.

Podemos ver no ensaio Proust de Samuel Beckett, um ponto de contato entre os dois escritores, ainda que Beckett opere em zonas (fronteiras) outras e de outros modos, pois essa descrição nos lembra aquilo que em sua poética é desvelamento de convenções do teatro. A solução proustiana estaria dada na obliteração do tempo, na abolição sensorial de suas fronteiras e na compreensão da arte enquanto necessidade ou ponte ao real como "união apropriada entre sujeito e objeto” (BECKETT, 2003, p. 81), parafraseando Baudelaire. O problema da gênese da criação, que o narrador da Busca sempre se colocou, é mais diretamente tratado por Beckett ao considerar a existência de uma percepção instintiva e inspirada, na identificação entre sujeito e objeto". Proust revelar-se-ia um impressionista, no que diz respeito ao livre jogo com a ordem dos acontecimentos em seu romance, desconsiderando uma cronologia meramente lógica e, nesse sentido, realista. A progressão dos eventos é lida como distorção da percepção, levada a certo grau de inteligibilidade, determinando uma estrutura instável de causa e efeito. 
Sendo assim, o estilo de longas frases, por vezes encadeando informações as mais diversas entre si, está de acordo com uma visão própria do tempo, mais do que vinculada ao virtuosismo técnico de bem escrever. Beckett conclui que no texto de Proust "a qualidade da linguagem é mais importante do que qualquer sistema ético ou estético. De fato, ele não faz qualquer esforço para separar forma e conteúdo. Um é a concretização do outro, a revelação de um mundo" (BECKETT, 2003, p. 94).

Ao final deste ensaio, a música emerge como elemento catalisador da Busca. As palavras de um libreto de ópera acabariam por corromper a sua qualidade de encarnar a Ideia, numa referência à concepção estética de Schopenhauer. O vaudeville é considerado mais completo, pois inaugura a comédia da enumeração excessiva, o que nos parece um elogio ao seu caráter lúdico e que se formaliza cenicamente pelas ações de alguns personagens clown das peças teatrais, a partir de Esperando Godot.

\section{Teatros do amor, teatros filosóficos}

Mas é do amor, que se tem por Outro (a), sempre um (a) desconhecido (a), ainda que se viva ao seu lado, dia após dia. Alguns diriam que é do amor que trata a busca pelo tempo perdido, pois nas observações de suas microevoluções, de seus subterfúgios, de sua inconstância, perde-se muito do tempo que poderia ser dedicado ao projeto, desde o início esboçado pelo narrador, da feitura de um livro, do trabalho, por assim dizer, que se opõe a esses "signos mundanos", subjetivos ou esvaziados de sentido prático.

Segundo Gilles Deleuze, em Proust e os signos, os três mundos que emitem signos na Busca são o da mundanidade, o do amor e o das qualidades sensíveis (as impressões e rememorações). Uma das leis do amor proustiano seria a da profundidade do ciúme, pois este conteria uma espécie de verdade e, ao mesmo tempo, de causa de tantos sofrimentos e desencontros, dada pela impossibilidade de fundir-se, de tornar-se uno com o outro. Assim sendo, põe-se a mente a devanear, procurar explicações, lançar-se às dúvidas mais insolúveis... "As mentiras do amado são os hieróglifos do amor" (DELEUZE, 2006, p. 09).

Pensando em seu amor por Gilberte e Albertine, ou ainda no interesse despertado inicialmente por Berma ou pela duquesa de Guermantes, temos uma espécie de encenação das armadilhas da idealização e de uma tentativa de captura do ser amado/desejado, que está bem representada na mininovela sobre Charles e Odette, Um amor de Swann, do primeiro livro, quando acompanhamos o gradual envolvimento do rico Swann com uma prostituta de luxo, a desejada Odette de Crécy. Após uma série de perseguições e cenas 


\section{Urdimento}

${ }^{5}$ Para Deleuze, outra qualidade do amor neste contexto é a de desvelar o desejo homossexual como algo mais profundo, ainda que sob a égide da interdição e do segredo, daí a metáfora de Sodoma e Gomorra para o quarto volume, no qual se exploram essas relações mais a fundo. de ciúme, Swann a conquista. O problema que ele enfrenta, após a realização desse desejo é o afastamento dos seus outros círculos sociais, mais abastados e nobres, em razão de seu casamento mundano. O desfecho para a novela de Swann inicia um outro momento deste mesmo ciclo de posses impossíveis, as do narrador e de seus contemporâneos ${ }^{5}$. Todavia, e não à toa, esse episódio foi transformado em um filme homônimo pelo diretor alemão Volker Schlöndorf, além de ser tido como um detalhado estudo sobre o ciúme.

Vejamos uma outra cena: quando Robert de Saint-Loup e sua amante Raquel encontrando-se juntos, convidam o narrador para ir ao teatro. O mundo tem aí como um duplo o teatro, "eu via uma outra peça muda e expressiva desenrolar-se por atrás da peça falada, que aliás me interessava, embora medíocre" (PROUST, 2007, p. 189). Essa tese se comprova na ilusão do amigo com a amante, ou ainda, da máscara social que Raquel portava com Saint-Loup e que sabia manipular com maestria. A dimensão de cena é dada pelo interesse do narrador em recortar os detalhes, observá-los e compará-los, tal e qual um diretor em processo de encenação, para profundas elaborações:

Essas individualidades efềmeras e vivazes que são as personagens de uma peça igualmente sedutora, a quem se ama, se admira, se lamenta, a quem se desejaria encontrar de novo, uma vez que se saiu do teatro, mas que já se desagregaram num comediante que não tem mais a condição que tinha na peça, num texto que já não mostra a fisionomia do comediante, num pó colorido que o lenço espana, que, numa palavra, viraram elementos que não têm mais nada delas, por causa de sua dissolução, consumidas logo após ofim do espetáculo, fazem, como a dissolução de um ente querido, duvidar da realidade do eu e meditar sobre o mistério da morte (PROUST, 2007, p. 189).

A partir disso, tentemos estabelecer um princípio de analogia entre essas relações e um princípio de teatralidade como o exposto por Jean-François Lyotard, no texto $O$ dente, a palma, de ocultamento e revelação. Tarefa que consiste num pequeno prelúdio a uma cena que reúne novas analogias entre o teatro (o lugar, a atração) e o amor como encantamento dos sentidos, em Proust. Lyotard traça alguns aspectos da teatralidade, a partir de um recorte histórico (os tratados de Zeami, as teses de Artaud e Brecht) e filosóficopsicanalítico (idéias pinçadas em Nietzsche, Pierce, Freud, Marx e outros).

Em outras palavras e algumas notas dispersas: o teatro é um lugar da ausência, um lugar em que os signos estão no lugar de algo que não está lá de fato, mas como representação, ilusão da presença e criação de um poder, no coração dessa ausência; ocultar e mostrar: eis a teatralidade; o exemplo do surrealista Hans Belmer: se tenho uma dor de dente, fecho a palma, e essa é 


\section{Urdimento}

uma relação libidinal, existe transferência de energia entre o fechar da palma da mão e a dor, mas esse ato pode ser revertido, codificado e regulado por um poder, como na lógica do capital; o projeto de Artaud para uma nova configuração da cena e da transfiguração do corpo do ator, uma ênfase na experiência como transcendência que, em menor escala, também pode ser encontrada em Zeami e no budismo, um tipo de ascetismo; a retórica marxista do teatro épico como uma solução que parece reduzir o teatro a uma função crítica, e nesse sentido, religiosa, alicerçada na crise do modernismo, uma solução destruída pelo capitalismo que a toma como mais um código; o dente e a palma, não têm um significado, são forças atuais, múltiplas e intensas, circulação de energia...como exprimí-las?; um teatro energético, descontínuo, como nas co-produções de dança por John Cage, Merce Cunningham e Robert Rauschenberg; questionamento das relações de poder na emissão e recepção dos signos; o sujeito é produzido pelo aparato performativo, ele desaparece quando o aparato desaparece; como é possível fazer, com alta intensidade e sem intenção, um teatro energético, com excesso ou falta de energia?

Pegando carona no estilo fragmentado do texto como artimanha para resumi-lo, refletimos aqui sobre tantos pontos porque eles são, em primeiro lugar, importantes na configuração de teorias para uma cena por vezes híbrida, corporalizada e não-linear, como ocorre no caso do teatro contemporâneo ${ }^{6}$. Importam também na medida em que criam novas bases para entender de que teatralidade Proust trata, critica, descreve e, sobretudo, parodia em seu romance. Pois ela molda o comportamento dos "atores" de sua comédia de rememorações, nos grandes teatros do amor e do tempo, que não têm uma, mas

${ }^{6}$ Ver a esse respeito a discussão de LEHMANN, 2007, p. 58-59. muitas formas e intensidades. Isto é, em sua escrita, os fatos são apresentados numa dinâmica próxima à multiplicidade proposta pelo teatro energético de Lyotard, sendo o "eu" narrativo uma construção de fragmentos de sua observação do real e das imagens que afloram dessa relação. Essas imagens nos fazem compreender o mundo como um teatro sempre em defasagem, uma imperfeição para e dos sentidos, que o apreendem ainda que se tente construir socialmente uma representação bem maquiada.

Desse modo, o próprio teatro da época é, por vezes, escolhido como metáfora de tal defasagem ou da exemplificação de suas estruturas de representação em relação, como no seguinte caso, com a experiência real:

Conhecemos, pelas pinturas antigas, o rosto dos antigos gregos, temos visto assírios no frontão de um palácio de Susa. Pois bem, quando encontramos, em sociedades orientais pertencentes a este ou àquele grupo, parece estarmos em presença de criaturas evocadas pela presença do espiritismo. Conhecíamos apenas uma imagem superficial; e eis que ela adquire profundidade, que se estende nas três dimensões, 
Urdimento

que se movimenta. A jovem dama grega, filha de um rico banqueiro, e atualmente em moda, tem um aspecto de uma dessas figurantes que, num bailado ao mesmo tempo estético e histórico, simbolizam em carne e osso a arte helênica; $e$ ainda no teatro a cenografia trivializa essas imagens; pelo contrário, o espetáculo a que nos faz assistir a entrada de uma turca, de um judeu num salão, animando as figuras, torna-as ainda mais estranhas, como se se tratasse efetivamente de seres evocados por um esforço mediúnico (PROUST, 2007, p. 208).

\section{Proust rindo-se das máscaras}

Em seu tex to “A imagem de Proust”, Walter Benjamin tece considerações sobre o surgimento da imagética na Busca como uma "realidade frágil e preciosa”, uma forma surrealista de descortinar as imitações do passado feudal que configuram a "máscara da grande burguesia” de então. Claro está para Benjamin, ao analisar certos aspectos biográficos do autor, que essa operação não foi fruto de poucos esforços, pois para contar tão detalhadamente era preciso estar infiltrado, e fazer da sátira e da observação engenhosa uma estratégia. "Como ele mesmo confidenciou uma vez: voir e désirer imiter eram para ele a mesma coisa” (BENJAMIN, 1994, p. 44).

$\mathrm{O}$ olhar que registra, por vezes, porta a lente do poeta satírico. O momento em que Proust escreveu era fértil de escritores das comédias de costumes do teatro de vaudeville, aquele que se passa nas ruas e praças, de um humor implacável. Desde Molière e Baudelaire, passando pela tradição de romanesca do século XIX, compõe-se um quadro de referências ao cômico em Proust, que foge ao escopo deste breve estudo.

Diversos críticos apontam como música, literatura e pintura estão presentes no romance de Proust em referências que se inter-relacionam ao longo de seus sete volumes. Segundo Rolf Renner, as alusões são parte da autoreflexividade do narrador, e sua erudição que se situa no campo de um gosto estético clássico e realista, com algumas alusões a pintores, como Vermeer, e a pinturas historicamente importantes, como a Gioconda, de Da Vinci, expressando-se também por seus personagens artistas, tais como o escritor Bergotte, o pintor Elstir e o próprio narrador Marcel. Entretanto, é no caráter escritural de encenar um movimento auto-reflexivo, como sugere Renner, que encontramos uma chave de leitura em que as condições da percepção como representação são realmente postas em cheque. 


\section{Referências bibliográficas}

BECKETT, Samuel. Proust. 1. ed. São Paulo: Cosac Naif, 2003.

BENJAMIN, Walter. A imagem de Proust. In: Magia e técnica, arte e política. Ensaios sobre literatura e história da cultura. Obras escolhidas. Vol. 1. 7. ed. São Paulo: Brasiliense, 1994.

DELEUZE, Gilles. Prouste os signos. 2. ed. Rio de Janeiro: Forense Universitária, 2006.

FARIAS JR., Manoel Moacir Rocha. Os silêncios na (dês-) composição da cena: poéticas de criação de e a partir de Samuel Beckett. 120f. Dissertação (Mestrado em Artes Cênicas) - Escola de Comunicação e Artes da Universidade de São Paulo, São Paulo, 2009.

LEHMANN, Hans-Thies. Teatro pós-dramático. 1. ed. São Paulo: Cosac Naif, 2008.

LYOTARD, Jean-François. The tooth, the palm. In: MURRAY, Thimothy. Mimesis, masochism and mime: the politics of theatricality in contemporary french thought. 1. ed. Michigan: University of Michigan Press, 2005.

PROUST, Marcel. No caminho de Swann. 1. ed. Rio de Janeiro: O Globo, 2003.

. À sombra das raparigas em flor. 1. ed. São Paulo: Globo, 2006.

O caminho de Guermantes. 1. ed. São Paulo: Globo, 2007.

MOTTA, Leda Tenório da. Proust: A violência sutil do riso. 1. ed. São Paulo: Perspectiva, 2007.

RENNER, Rolf. Arte e crítica de arte na Recherche. In: PROUST, Marcel. À sombra das raparigas em flor.1. ed. Rio de Janeiro: Globo, 2006. 


\section{NORMAS PARA PUBLICAÇÃO DE ARTIGOS}

A Revista Urdimento é uma publicação do Programa de PósGraduação em Teatro da Universidade do Estado de Santa Catarina e reúne artigos que contribuiem para a pesquisa na área das artes cênicas.

A Urdimento recebe as colaborações em fluxo contínuo que são analisadas pelo Conselho Editorial. As seguintes normas técnicas devem ser observadas para a publicação das contribuições.

1) Os artigos devem ter no mínimo 8 e máximo 12 laudas. Resenhas de livros entre 3 e 4 laudas. Os textos deverão ser digitados com letra Times New Roman, tamanho 12, com espaçamento 1,5 cm em Word para Windows (ou compatível).

2) Os colaboradores devem incluir dados especificando as atividades que exercem, a instituição (se for o caso) em que trabalham e dados básicos dos respectivos currículos.

3) Solicita-se clareza e objetividade nos títulos.

4) Os artigos devem vir acompanhados de resumo com no máximo de 6 linhas e 3 palavras-chaves, ambos com as respectivas traduções para o inglês.

5) O envio do artigo original implica na autorização para publicação, tanto na forma imprensa como digital da revista.

6) Notas explicativas serão aceitas desde que sejam imprescindíveis e breves. As citações no corpo do texto que sejam superiores a 5 linhas devem ser digitadas em espaço simples com tamanho 10 em itálico. As citações no corpo do texto devem seguir a formatação (AUTOR, 2008, p.1).

7) Todas as palavras em língua estrangeira devem estar em itálico.

8) As notas de rodapé devem ser apresentadas no fim de cada página e numeradas em algarismos arábicos.

9) Caso os artigos incluam fotos, desenhos ou materiais gráficos 
da autoria de terceiros, é indispensável carta de autorização. O material deverá vir acompanho de legendas de identificação. $\mathrm{O}$ material gráfico deve ser reduzido ao mínimo indispensável, em formato JPG e com resolução de 300 dpi, enviadas em arquivos separados do texto. Somente serão publicadas imagens em preto e branco.

10) O material para a publicação deverá ser encaminhado em duas vias impressas e uma em formato digital (programa word) para o e-mail urdimento@udesc.br aos cuidados da revista.

Endereço para correspondência e envio de colaborações:

\section{Revista Urdimento}

Programa de Pós-Graduação em Teatro - UDESC

Av. Madre Benvenuta, 1.907 - Itacorubi

88.035-001 - Florianópolis - SC

E-mail: urdimento@udesc.br

\section{Normas para citação de referência bibliográfica:}

\section{Livros}

SOBRENOME, Prenomes do autor. Título: subtítulo. edição. Local: editor, ano de publicação.

\section{Teses/ Dissertações/Monografias}

SOBRENOME, Prenomes do autor. Título: subtítulo. ano. $\mathrm{n}^{\circ}$ total de páginas.Tese, Dissertação ou Monografia (grau e área) - Unidade de Ensino, Instituição, Local e ano.

\section{Artigos de periódicos na internet}

SOBRENOME, Prenomes do autor. Título do artigo. Título da Revista, local, volume, número, páginas do artigo, mês e ano de publicação. Notas. Disponível em: <http://www....> Acesso em: dia mês (abreviado) ano, hora: minutos.

\section{Artigos}

SOBRENOME, Prenomes do autor do artigo. Título do artigo. Título da Revista, local, volume, número, páginas do artigo (inicial e final), mês e ano da publicação do artigo. 
Realização:

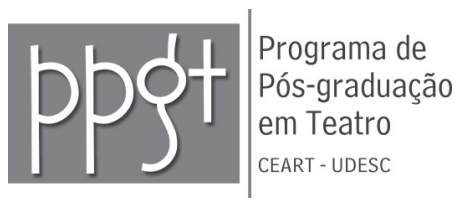

Programa de Pós-Graduação em Teatro

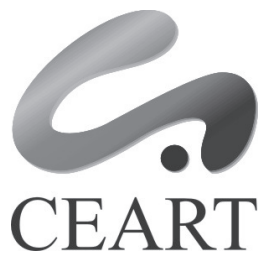

Centro de Artes 
Este projeto editorial foi criado eletronicamente utilizando o software Adobe In Design CS3. As famílias tipográficas Bell MT e BellCent são utilizadas em toda esta revista. 